\title{
Can people affected by leprosy at risk of developing plantar ulcers be identified? A field study from central Ethiopia
}

\author{
WYBREN FEENSTRA*, STEVEN VAN DE VIJVER**, \\ CATHERINE BENBOW $* * *$, ASSEFA AMENU*** \& \\ PAUL SAUNDERSON*** \\ *Medical Faculty, University of Utrecht, The Netherlands \\ **Medical Faculty, University of Groningen, The Netherlands \\ ***ALERT, PO Box 165, Addis Ababa, Ethiopia
}

Accepted for publication 10 April 2001

Summary In the ALERT leprosy control programme, 75 people affected by leprosy, in three different geographical areas, were investigated. Each person was documented as having anaesthesia to the $10 \mathrm{~g}$ monofilament. The study sought to determine why some people developed ulcers whilst others did not. According to the records, 43 had an ulcer during the last 5 years but 32 had never had an ulcer. In order to examine protective sensation on the sole of the foot, various sensory modalities were tested and the functional anatomy of the foot was examined. The results showed, as may be expected, that it is not possible to define a specific threshold for protective sensation that could be applied to all cases. Some people with only slightly diminished sensation developed ulcers, while many others with almost complete anaesthesia remained ulcer-free. In these rural communities, being a farmer reduced the risk of developing an ulcer, but no other demographic features were significant. Graded monofilaments were found to be the most appropriate test, with loss of sensation at any of five points tested being a 'positive' result. The $10 \mathrm{~g}$ filament was the most sensitive, but only $43 \%$ of feet identified by this test actually developed an ulcer. As people with partial loss of sensation were excluded from this study, this figure may be lower under programme conditions. The $50 \mathrm{~g}$ and $100 \mathrm{~g}$ filaments decrease the number of feet identified as at risk, but increase the percentage which actually develop an ulcer, to $46 \%$ and $49 \%$, respectively. An appropriate test for selecting those for special programmes which may have a limited capacity, for example the provision of subsidized footwear or involvement in self-care groups, would be a $100 \mathrm{~g}$ filament, which would detect $86 \%$ of those feet likely to develop an ulcer, while reducing the number of those selected who are not at great risk. Vibrometry was found to be no better than graded filaments and an examination of functional anatomy did not help in identifying those at risk.

* Correspondence to: Catherine Benbow, The Floors, Bourton, Much Wenlock, Shropshire TF13 6QN, UK (email: BenbowFloors@aol.com). 


\section{Introduction}

Plantar ulcers are well recognized as a major cause of disability in leprosy. Ulcers are the result of deformity and/or loss of protective sensation and are caused by repetitive moderate stress, direct trauma, pressure, burns and walking on infected feet. ${ }^{1}$

The presence of protective sensation allows an individual to minimize injury. There are many sensory modalities involved in this mechanism, including the cortical interpretation of these modalities and the resultant response. There is therefore much individual variation in what constitutes protective sensation. ${ }^{2}$

The characteristics of protective sensation and the relationship between it and the development of plantar ulcers are unclear. Birke and Sims suggest that the use of graded monofilaments is the most appropriate method of establishing a sensory threshold in the foot. They examined 132 plantar ulcer sites and concluded that the $10 \mathrm{~g}$ filament would identify all these sites and therefore indicate loss of protective sensation. ${ }^{3}$

Malavuja et al. compared feet of leprosy patients with and without ulcers and found that while there were no ulcers at points with 'normal' sensation (able to feel a $2 \mathrm{~g}$ filament), the majority ( $83 \%$ ) of sites with 'complete anaesthesia' (unable to feel an $85 \mathrm{~g}$ filament) also had no ulcers. ${ }^{4}$ Others have shown that having an abnormal anatomy due to paralyses of intrinsic and/or extrinsic muscles of the foot is a risk factor for plantar ulceration. ${ }^{5}$ The influence of socioeconomic circumstances is also likely to be important in determining who is at greater risk of developing an ulcer. ${ }^{6}$

Various methods of testing the different sensory modalities in the foot have been developed, many of them being too cumbersome for use in the field and general health clinics. Light touch sensation is widely studied, using graded monofilaments. Two-point discrimination may be used for the hand, but is unsuitable for the foot. ${ }^{7}$ Vibration sense can be measured using a vibrometer, or less precisely with a tuning fork. ${ }^{8}$ Pain sensation can be assessed with a pinprick, but this could not now become a routine test because of the risk of transmitting HIV.

Patients with diabetes are also at risk of developing plantar ulcers due to loss of protective sensation. The $10 \mathrm{~g}$ nylon monofilament is becoming a standard screening tool in diabetic clinics to identify those at risk of ulceration. ${ }^{9,10}$ While loss of protective sensation occurs in both leprosy and diabetes, the socio-economic setting of the two diseases is very different. The search for better management of diabetic complications is mainly taking place in the developed world, while leprosy is a problem most common in developing countries. The characteristics of a screening test for loss of protective sensation must relate to the circumstances in which it will be used. In diabetes, clinicians require a sensitive test that will not miss cases likely to ulcerate; the number of false positives selected by the test is unimportant, as the resources are available to provide for all. The $10 \mathrm{~g}$ monofilament seems to be an ideal test in this setting, being simple, reproducible and valid. ${ }^{10}$

The current situation regarding plantar ulceration in leprosy is, however, very different. In many countries, subsidized protective footwear is beginning to be made available (usually with an increasing proportion of the cost charged to patients) and other initiatives, such as self-care groups, are being developed, all within the context of limited resources. ${ }^{6}$ What is needed in this situation is a screening test which will reduce the number of false positive results and enable resources to be targeted at those with a high risk of plantar ulceration.

ALERT has had a footwear programme for some years and has used the $10 \mathrm{~g}$ monofilament as the criterion for the provision of footwear. Anyone with one or more points of loss 
of sensation is eligible for footwear. Results have been gratifying, ${ }^{6}$ but it is noted that many people who have never had an ulcer and seem to have a low risk of developing one, are being given subsidized footwear, because they qualify on the grounds of anaesthesia to the $10 \mathrm{~g}$ monofilament. This study was therefore set up to look for a screening test which would be more selective than the $10 \mathrm{~g}$ monofilament, but which would not miss many cases likely to ulcerate.

\section{Materials and methods}

Leprosy patients were selected from self-care groups in central Ethiopia, located near three towns: Sheshemane, Mukadima and Wolkite. Inclusion criteria were: age over 15 years, a history of leprosy of more than 5 years, complete loss of sensation to the $10 \mathrm{~g}$ monofilament on at least one foot and no more than a minimal amount of tissue loss on either foot. Seventyfive patients meeting these criteria were identified.

Demographic and other relevant information was recorded. The positions of ulcers, scars and cracks were noted, and the presence of sweating and clawing of the toes was recorded. Previous medical records were also examined for evidence of ulceration.

Touch, pain and vibration sense were each examined at five points (big toe, 1st metatarsal head, 5th metatarsal head, 5th metatarsal base and the heel). These are pressure points and risk positions for developing ulcers. If there was an ulcer at any point, the nearest area of intact skin was tested.

Touch sensation was tested using 10, 50, 100 and $300 \mathrm{~g}$ monofilaments. Vibration sense was tested with a bio-thesiometer, with a range of $0-50 \mathrm{~V}$ (0-25.5 microns of motion), at a frequency of $120 \mathrm{~Hz}$; a tuning fork with a frequency of $256 \mathrm{~Hz}$ was used for comparison. A portable generator was used to provide power for the vibrometer.

The range of movement of the ankle joint (dorsi- and plantarflexion) and subtalar joint (inversion and eversion) was classified into three categories (hypermobile, normal or restricted). Proprioception sense at the ankle joint was examined clinically by asking the patient (first with eyes open, then with eyes covered) whether the foot was being moved up or down. The range of extension of the big toe was measured and the strength of dorsiflexion of the foot was assessed.

The walking pattern was inspected in the following order: heel first, lateral side, fore foot and big toe push-off. The pattern was described as abnormal if one or more phase was absent. The length and symmetry of the stride were inspected. The position of the tendoachilles attachment to the calcaneus was inspected in a natural standing position and was classified into five categories (severe supination, mild supination, normal, mild pronation, severe pronation). For the analysis severe supination or pronation were taken to be abnormal, while mild supination or pronation were included in the normal group. Footprints of both feet were taken during a natural walking pattern, using a Berkemann Harris Mat.

The data were analysed using Epi Info v6.

\section{Results}

Of the 75 patients, 32 had never had an ulcer and 43 had had a documented ulcer in the previous 5 years. Amongst the 43 patients with ulcers, there were 51 feet with ulcers or a 
Table 1. Baseline characteristics $(n=75)$

\begin{tabular}{lcc}
\hline & Those without ulcers & $\begin{array}{c}\text { Those with ulcers, now } \\
\text { or in the past 5 years }\end{array}$ \\
\hline Number & 32 & 43 \\
Male & 17 & 32 \\
Female & 15 & 11 \\
Farmers & 25 & 23 \\
Non-farmers & 7 & 20 \\
Age $<50$ & 18 & 26 \\
Age $>50$ & 14 & 17 \\
Area of residence & & \\
Shashamene & 19 & 24 \\
Mukadima & 5 & 12 \\
Wolkite & 8 & 7 \\
\hline
\end{tabular}

recorded history of ulceration. Table 1 shows the characteristics of the study population. For none of these factors was the difference significant, except for occupation, with non-farmers having an increased risk of developing an ulcer [OR: $3 \cdot 1$ (95\% CI: $1 \cdot 0-10 \cdot 0)$.]

Table 2 shows the results of sensation testing at each point using different methods. In those with ulcers, 51 points had ulcers at some time in the last 5 years (there are 43 patients and eight have an ulcer on both feet); if there was more than one ulcer on a foot, only the larger one was used for this exercise. Amongst those without ulcers, 320 points never had an ulcer (five points per foot $\times 32$ patients).

Various criteria could be utilized as a screening test to identify those patients most at risk of developing an ulcer. Interventions could be designed for patients identified by these means. Table 3 examines potential tests in terms of their ability to identify those at risk, taking individual feet as the unit for testing. For each test, the result would be 'positive' if the person is unable to feel it at one or more of the five points on the foot being

Table 2. Analysis by pressure point $(n=371)$. For touch and vibrometry, the site is categorized under the lowest reading that could be felt

\begin{tabular}{|c|c|c|c|c|c|c|c|c|c|c|c|c|}
\hline \multirow{4}{*}{$\begin{array}{l}\text { Touch } \\
\text { Filament } \\
\text { Ulcer } \\
\text { Non-ulcer }\end{array}$} & & \multirow[b]{2}{*}{$50 \mathrm{~g}$} & \multirow{2}{*}{\multicolumn{2}{|c|}{$100 \mathrm{~g}$}} & \multirow[b]{2}{*}{$300 \mathrm{~g}$} & \multirow{2}{*}{\multicolumn{2}{|c|}{ None felt }} & \multirow[b]{2}{*}{ Total } & & & \\
\hline & \multicolumn{2}{|c|}{$10 \mathrm{~g}$} & & & & & & & & & & \\
\hline & \multirow{2}{*}{\multicolumn{2}{|c|}{$\begin{array}{r}2 \\
22\end{array}$}} & 8 & \multicolumn{2}{|c|}{3} & 5 & \multicolumn{2}{|c|}{33} & \multicolumn{2}{|c|}{51} & & \\
\hline & & & 100 & \multicolumn{2}{|c|}{72} & 50 & \multicolumn{2}{|c|}{76} & \multicolumn{2}{|l|}{320} & & \\
\hline \multicolumn{13}{|l|}{ Vibrometry } \\
\hline $\begin{array}{l}\text { Volts } \\
\text { (microns) }\end{array}$ & $\begin{array}{l}5 \\
(0 \cdot 25)\end{array}$ & $\begin{array}{l}10 \\
(1 \cdot 0)\end{array}$ & $\begin{array}{l}15 \\
(2 \cdot 2)\end{array}$ & $\begin{array}{l}20 \\
(4 \cdot 0)\end{array}$ & $\begin{array}{l}25 \\
(6 \cdot 4)\end{array}$ & $\begin{array}{l}30 \\
(9 \cdot 2)\end{array}$ & $\begin{array}{c}35 \\
(12 \cdot 5)\end{array}$ & $\begin{array}{c}40 \\
(16 \cdot 4)\end{array}$ & $\begin{array}{l}45 \\
(20 \cdot 8)\end{array}$ & $\begin{array}{c}50 \\
(25 \cdot 5)\end{array}$ & None felt & Total \\
\hline Ulcer & 0 & 0 & 0 & 1 & 2 & 3 & 1 & 7 & 3 & 9 & 25 & 51 \\
\hline Non-ulcer & 2 & 8 & 11 & 19 & 31 & 29 & 27 & 29 & 20 & 46 & 98 & 320 \\
\hline \multicolumn{13}{|l|}{ Tuning fork } \\
\hline Felt & Yes & No & Total & & & & & & & & & \\
\hline Ulcer & 14 & 37 & 51 & & & & & & & & & \\
\hline Non-ulcer & 145 & 175 & 320 & & & & & & & & & \\
\hline
\end{tabular}


Table 3. The performance of possible screening tests for identifying those at risk of plantar ulceration. If any of five pressure points on the sole of the foot cannot feel the stimulus, the test is 'positive'

\begin{tabular}{lccc}
\hline & $\begin{array}{c}\text { Number of feet with a } \\
\text { 'positive' result } \\
(n=115)\end{array}$ & \multicolumn{2}{c}{$\begin{array}{c}\text { Number }(\%) \text { of } \\
\text { 'positive' feet } \\
\text { developing ulcers }\end{array}$} \\
\hline Test & 112 & 48 & $(43)$ \\
$10 \mathrm{~g}$ & 100 & 46 & $(46)$ \\
$50 \mathrm{~g}$ & 90 & 44 & $(49)$ \\
$100 \mathrm{~g}$ & 74 & 40 & $(54)$ \\
$300 \mathrm{~g}$ & 103 & 48 & $(47)$ \\
Tuning fork (TF) & 105 & 48 & $(46)$ \\
Vibrometry 30 V & 96 & 43 & $(45)$ \\
Vibrometry 40 V & 75 & 37 & $(49)$ \\
Vibrometry 50 V & & & \\
\hline
\end{tabular}

tested-a 'positive' test would indicate an increased risk of developing an ulcer. The number of feet testing 'positive' is given, followed by the number (and percentage) of feet which developed ulcers. The percentage with ulcers rises with the heavier, or less sensitive filaments.

When the function of the foot as a whole was analysed, two groups were considered: the 51 feet with recent ulcers and the 64 feet with no history of ulcers. Table 4 shows the results of this analysis.

While the stride was not different between the two groups, an abnormal walking pattern was associated with the development of ulcers, although it is unclear whether the abnormalities seen are causative or have developed as a result of the ulceration. The most common abnormality of walking pattern was the absence of a normal push-off from the big toe.

The prints from the Harris mat were examined, but the quality was generally rather poor for technical reasons. Of the 29 ulcer points with a reasonable footprint, only $15(52 \%)$ had pressure points seen on the print and of the 27 feet which had never had an ulcer, 10 $(37 \%)$ pressure points were identified.

During the course of the study, it was found that it was difficult to make reliable

Table 4. Function of the foot as a whole in cases and controls $(n=51+64=115)$

\begin{tabular}{|c|c|c|c|c|c|}
\hline & \multicolumn{2}{|c|}{ Non-ulcer group } & \multicolumn{2}{|c|}{ Ulcer group } & \multirow{2}{*}{$\begin{array}{r}\text { Odds ratio } \\
(95 \% \mathrm{CI})\end{array}$} \\
\hline & Normal & Abnormal & Normal & Abnormal & \\
\hline Ankle: range of movement: dorsiflexion & 55 & 9 & 36 & 15 & NS \\
\hline Ankle: range of movement: plantarflexion & 47 & 17 & 41 & 10 & NS \\
\hline Ankle proprioception & 59 & 5 & 49 & 2 & NS \\
\hline Position of the tendo-achilles & 60 & 4 & 47 & 4 & NS \\
\hline Eversion of sub-talar joint & 37 & 27 & 27 & 24 & NS \\
\hline Inversion of sub-talar joint & 47 & 17 & 29 & 22 & NS \\
\hline Extension of the big toe & 44 & 20 & 26 & 25 & NS \\
\hline Walking pattern & 38 & 26 & 20 & 31 & $\begin{array}{l}2 \cdot 27 \\
(1.0-5 \cdot 16)\end{array}$ \\
\hline
\end{tabular}


assessments of sweating and the intrinsic muscles of the foot. These items were therefore omitted from the analysis.

\section{Discussion}

In terms of sensation, light touch, using graded monofilaments, was the most valuable test in making a distinction between the ulcer and non-ulcer group. It is not possible, however, to make a firm statement about people at risk of getting ulcers. As can be seen in Table 2, two patients who felt the $10 \mathrm{~g}$ filament at a certain point have developed ulcers at that point and many patients unable to feel the $300 \mathrm{~g}$ filament have not developed any ulcers.

Vibrometry was found to be no better than graded monofilaments in identifying those at risk and it is much more difficult to use because of the need for electricity. The tuning fork gave similar results to vibrometry at an amplitude of 30-40 V. The Harris mat did not perform as well as the other tests and requires considerable skill both in carrying out the test and interpreting the results. In this group of patients without significant tissue loss or deformity, examination of the anatomy and function of the foot was unable to identify patients at risk.

Table 3 shows the results of using the worst result of all five points tested on each foot as the test result for that foot. It should be noted that one of the inclusion criteria for this study was complete loss of sensation to the $10 \mathrm{~g}$ monofilament on at least one foot. In fact, only 11 of the 64 feet without ulcers had any points that could feel the $10 \mathrm{~g}$ monofilament. In the routine programme, many patients have incomplete loss of sensation, but are currently eligible to receive protective footwear if there is any degree of sensory loss as measured by the $10 \mathrm{~g}$ monofilament. Thus under programme conditions, the figures in Table 3 for the $10 \mathrm{~g}$ test may be somewhat different, with a rather smaller percentage of those identified as at risk actually developing ulcers.

Various interventions are being developed to assist people affected by leprosy to protect themselves from further damage, including the provision of protective footwear and the formation of self-care groups. The cost of keeping all the patients with sole sensory loss supplied with free or subsidized footwear is likely to be prohibitive, ${ }^{11}$ as is the cost of setting up and facilitating self-care groups. In addition to cost, the logistic difficulties involved in dealing with large numbers of patients may make a programme impossible to implement. A method of more accurately targeting such support would be valuable in many programmes.

The $10 \mathrm{~g}$ filament will identify almost all cases at risk of developing an ulcer and a certain number of false positive cases as well. A more appropriate test, at least in the initial phase of a footwear programme, would be the $100 \mathrm{~g}$ monofilament, which will identify $86 \%$ of patients needing special care, but fewer of those without ulceration. Obviously if such a criterion were to be used for any particular intervention, patients who are known to have had an ulcer would also be included, whatever their test results.

In conclusion, this study confirms the view of others that nylon monofilaments are the most appropriate means of testing for protective sensation. ${ }^{3,10}$ Other methods of testing, such as vibrometry and assessment of the functional anatomy of the foot, are no more discriminating. The $10 \mathrm{~g}$ monofilament is a sensitive test and should be used in situations where all those identified by the screening process can be managed effectively, but this study shows that it will select many people who do not appear to be at risk of plantar ulceration. In programmes with limited resources and large numbers of patients, the $100 \mathrm{~g}$ monofilament 
would be a more selective test that would reduce the numbers of false positives while retaining a high degree of sensitivity.

\section{Acknowledgements}

We thank ALERT for facilitating the research and staff members Negussie H/Mariam, Tefera Tamiru, Ketema Bedada and Haile Meskal Damite for helping with the field work. We also thank Dr Roland Kazen for analysing the Harris mat footprints and Dr Peter Byass for statistical advice. W.F. and S.vdV. were assisted financially by The Damien Foundation and Gastman-Wieger Stichting.

\section{References}

${ }^{1}$ Kazen RO. Management of plantar ulcers in leprosy. Lepr Rev, 1999; 70: 63-69.

2 Brand PW. Insensitive feet: a practical handbook on foot problems in leprosy. The Leprosy Mission International, 1989.

${ }^{3}$ Birke JA, Sims DS. Plantar sensory threshold in the ulcerative foot. Lepr Rev, 1986; 57: 261-267.

${ }^{4}$ Malaviya GN, Husain S, Mishra B et al. Protective sensibility-its monofilament nylon threshold equivalents in leprosy patients. Ind J Lepr, 1997; 69: 149-157.

5 Cross H, Sane S, Dey A, Kulkarni VN. The efficacy of podiatric orthoses as an adjunct to the treatment of plantar ulceration in leprosy. Lepr Rev, 1995; 66: 144-157.

6 Seboka G, Saunderson PR. Cost-effective footwear for leprosy control programmes: a study in rural Ethiopia. Lepr Rev, 1996; 67: 208-216.

7 Kets CM, van Leerdam ME, van Brakel WH et al. Reference values for touch sensibility thresholds in healthy Nepalese volunteers. Lepr Rev, 1996; 67: 28-38.

8 Klenerman P, Hammond C. Vibration sensation in leprosy patches. Int J Lepr, 1988; 56: 466-468.

9 Armstrong DG, Lavery LA, Vela SA et al. Choosing a practical screening instrument to identify patients at risk for diabetic foot ulceration. Arch Int Med, 1998; 158: 289-292.

10 Smieja M, Hunt DL, Edelman D et al. Clinical examination for the detection of protective sensation in the feet of diabetic patients. International Cooperative Group for Clinical Examination Research. J Gen Int Med, 1999; 14: 418-424.

11 Watson J. Disability control in a leprosy control programme. Lepr Rev, 1989; 60: 169-177. 